\title{
Differential expression of c-Met between primary and metastatic sites in clear-cell renal cell carcinoma and its association with PD-L1 expression
}

\author{
Aly-Khan A. Lalani ${ }^{1}$, Kathryn P. Gray², Laurence Albiges ${ }^{3}$, Marcella Callea ${ }^{4}$ Jean- \\ Christophe Pignon ${ }^{5}$, Soumitro Pal ${ }^{6}$, Mamta Gupta7, Rupal S. Bhatt ${ }^{8}$, David F. \\ McDermott $^{8}$, Michael B. Atkins ${ }^{9}$, G.F. Vande Woude ${ }^{10}$, Lauren C. Harshman ${ }^{1}$, Toni \\ K. Choueiri ${ }^{1, *}$ and Sabina Signoretti ${ }^{5, *}$ \\ ${ }^{1}$ Lank Center for Genitourinary Oncology, Dana-Farber Cancer Institute, Boston, MA, USA \\ ${ }^{2}$ Department of Biostatistics and Computational Biology, Dana-Farber Cancer Institute, Boston, MA, USA \\ ${ }^{3}$ Institut Goustave Roussy, Villejuif, France \\ ${ }^{4}$ Department of Pathology, Ospedale San Raffaele, Milan, Italy \\ ${ }^{5}$ Department of Pathology, Brigham and Women's Hospital, Boston, MA, USA \\ ${ }^{6}$ Division of Nephrology, Boston Children's Hospital, Boston, MA, USA \\ ${ }^{7}$ Department of Pathology, Beth Israel Deaconess Medical Center, Boston, MA, USA \\ ${ }^{8}$ Division of Hematology/Oncology, Beth Israel Deaconess Medical Center, Boston, MA, USA \\ ${ }^{9}$ Georgetown Lombardi Comprehensive Cancer Center, Washington D.C., USA \\ ${ }^{10}$ Van Andel Research Institute, Grand Rapids, MA, USA \\ *Co-senior authors contributed equally to this work \\ Correspondence to: Toni K. Choueiri, email: Toni_Choueiri@dfci.harvard.edu \\ Sabina Signoretti, email: ssignoretti@partners.org
}

Keywords: $c-M e t, P D-L 1$, primary, metastasis, renal cell carcinoma

Received: August 24, 2017 Accepted: September 29, 2017

Published: October 23, 2017

Copyright: Lalani et al. This is an open-access article distributed under the terms of the Creative Commons Attribution License 3.0 (CC BY 3.0), which permits unrestricted use, distribution, and reproduction in any medium, provided the original author and source are credited.

\section{ABSTRACT}

In preclinical models, c-Met promotes survival of renal cancer cells through the regulation of programmed death-ligand 1 (PD-L1). However, this relationship in human clear cell renal cell carcinoma (CCRCC) is not well characterized. We evaluated c-Met expression in ccRCC patients using paired primary and metastatic samples and assessed the association with PD-L1 expression and other clinical features. Areas with predominant and highest Fuhrman nuclear grade (FNG) were selected. c-Met expression was evaluated by IHC using an anti-Met monoclonal antibody (MET4 Ab) and calculated by a combined score (CS, 0-300): intensity of c-Met staining (0-3) $x$ $\%$ of positive cells (0-100). PD-L1 expression in tumor cells was previously assessed by IHC and PD-L1+ was defined as PD-L1 > 0\% positive cells. Our cohort consisted of 45 pairs of primary and metastatic ccRCC samples. Overall, c-Met expression was higher in metastatic sites compared to primary sites (average c-Met CS: 55 vs. 28, $p=$ 0.0003 ). Higher c-Met expression was associated with higher FNG (4 vs. 3 ) in primary tumors (average c-Met CS: 52 vs. 20, $p=0.04$ ). c-Met expression was numerically greater in PD-L1+ vs. PD-L1- tumors. Higher c-Met expression in metastatic sites compared to primary tumors suggests that testing for biomarkers of response to c-Met inhibitors should be conducted in metastases. While higher c-Met expression in PD-L1+ tumors requires further investigation, it supports exploring these targets in combination clinical trials. 


\section{INTRODUCTION}

The cell-surface receptor tyrosine kinase c-Met is encoded by the $c-M E T$ proto-oncogene and is involved in several key functions, including cell growth, cell differentiation, neo-vascularization, and tissue repair [1]. c-Met and its only known ligand, hepatocyte growth factor (HGF), have been implicated in tumor development, invasion, migration and angiogenesis in solid tumor malignancies, including renal cell carcinoma (RCC) $[2,3]$. The prognostic relevance of c-Met expression has been explored in several tumor types and shown to be associated with poorer outcomes [4, 5]. In RCC, high c-Met expression was reported to be an independent predictor of survival in 330 nephrectomy cases using quantitative immunofluorescence [6]. In the metastatic RCC (mRCC) setting, c- Met expression also appears to be associated with worse outcomes in a retrospective cohort of patients treated with sunitinib, an antiangiogenic agent against vascular endothelial growth factor receptor (VEGFR) [7].

C-Met and the tyrosine-kinase AXL can be upregulated in RCC and have been shown to play a possible role in the development of resistance to VEGFR inhibitors making these pathways rational targets for therapeutic trials [8-13]. Cabozantinib, an oral, smallmolecule inhibitor of VEGFR, MET, and AXL, improved overall survival compared to everolimus in previouslytreated patients with advanced RCC [14, 15]. A Phase II study also showed the promise of cabozantinib to improve progression-free survival (PFS) and response rates in patients with untreated intermediate and poor risk mRCC compared to standard of care sunitinib [16]. With the expanding treatment armament and the likely importance of c-Met in controlling mRCC, the quest for an optimal model to assess for predictive biomarkers for c-Met inhibition has emerged.

The HGF/c-Met pathway has also been implicated in attenuating inflammatory responses, which suggests potential for immunomodulation with inhibition of this pathway $[17,18]$. Preclinical models have shown that c-Met expression promotes the upregulation of programmed death-ligand 1 (PD-L1) and that this increase protects renal cancer cells from immune-mediated cytotoxicity [19]. However, the relationship between c-Met and PD-L1 in human mRCC has not been well characterized.

In this context, and given the known tumoral heterogeneity in this disease [20], we aimed to compare the expression of c-Met between paired primary and metastatic sites in clear-cell RCC (ccRCC) tissues. We also evaluated the potential association of c-Met expression with clinicopathological factors and PD-L1 expression in tumor cells in both primary and metastatic sites. In a descriptive analysis of a subset of patients treated with VEGF targeted therapy (VEGF-TT), we report on the effect of c-Met status on clinical outcomes and the effect of treatment in between primary and metastatic sampling on c-Met expression.

\section{RESULTS}

\section{Patient population and tumor tissue selection}

We identified 45 patients with both primary and metastatic lesions available for analysis. Patient characteristics at the time of primary surgery are summarized in Table 1. Median age was 58 and $64 \%$ of patients were male. Pathologic T-stage at diagnosis was T1/T2 in 17 (38\%) patients and T3/T4 in $25(56 \%)$. No FNG I or II were reported in the cohort; 32 patients had FNG III and 13 had FNG IV. Metastatic sites included: lung $(n=14)$, bone $(n=4)$, lymph nodes $(n=10)$, soft tissues $(n=5)$, adrenal gland $(n=6)$, pleura $(n=3)$, brain $(n=1)$, thyroid $(n=1)$, and others $(n=10)$. Although most primary tumors had only one corresponding metastasis, 10 cases $(22 \%)$ had two or more metastatic lesions that could be retrieved, which resulted in a total of 54 metastases that were analyzed.

\section{c-Met expression is increased in metastases compared to primary tumors and is associated with higher FNG}

c-Met expression (average c-Met combined score $(\mathrm{CS})>0)$ was detected in 34 of $45(75.6 \%)$ primary ccRCC samples and 41 of 54 (75.9\%) metastases. Overall, c-Met expression levels were higher in metastatic sites compared to paired primary tissues (average c-Met CS (interquartile range, IQR): $55(30,83)$ vs. $28(10,55)$, $p=0.0003$, respectively) (Figure 1A and 1B). Higher c-Met expression in primary tumors was shown to be associated with higher FNG (4 vs 3; average c-Met CS: 52 vs. $20, p=0.04$, respectively) and patients with T-stage T3-T4 appear to have higher c-Met expressions compared to those with Tx-T2 (average c-Met CS: 30 vs. $24, p=0.13$, respectively) (Table 2).

\section{Association of c-Met expression with PD-L1 expression}

Of the 45 pairs of samples available for c-Met analysis, $13(29 \%)$ displayed PD-L1 positivity in the primary tumor and 9 cases $(20 \%)$ were PD-L1 positive in paired metastases, including 7 cases (16\%) with PD-L1 positivity in both primary tumors and metastases. PD-L1 positive tumors had numerically greater c-Met expression than PD-L1 negative tumors in both primary (average c-Met CS: 30 vs. $24, p=0.34$, respectively) and metastatic sites (average c-Met CS: 60 vs. 51, $p=0.45$, respectively), although these differences were not statistically significant (Table 2, Figure 2, Figure 3A-3D). 


\begin{tabular}{|c|c|}
\hline Characteristics & $\begin{array}{c}\text { Total } n=45 \\
\text { Patients, } n(\%)\end{array}$ \\
\hline \multicolumn{2}{|l|}{ Gender } \\
\hline Male & $29(64)$ \\
\hline Female & $16(36)$ \\
\hline Median age at primary surgery, y (range) & $58(49-62)$ \\
\hline \multicolumn{2}{|l|}{ T stage } \\
\hline $\mathrm{T} 1$ & $3(7)$ \\
\hline $\mathrm{T} 2$ & $14(31)$ \\
\hline $\mathrm{T} 3$ & $21(47)$ \\
\hline $\mathrm{T} 4$ & $4(9)$ \\
\hline Tx & $3(7)$ \\
\hline \multicolumn{2}{|l|}{$\mathrm{N}$ stage } \\
\hline N0 & $12(27)$ \\
\hline N1 & $13(29)$ \\
\hline $\mathrm{Nx}$ & $20(44)$ \\
\hline \multicolumn{2}{|l|}{ Fuhrman nuclear grade (FNG) } \\
\hline III & $32(71)$ \\
\hline IV & $13(29)$ \\
\hline \multicolumn{2}{|l|}{ Number of metastatic sites analyzed per case } \\
\hline 1 & $35(78)$ \\
\hline 2 & $6(13)$ \\
\hline$\geq 3$ & $4(9)$ \\
\hline \multicolumn{2}{|l|}{ Systemic therapy } \\
\hline VEGF targeted therapy (VEGF-TT) & $20(44)$ \\
\hline Vaccine-based or other therapies & $16(36)$ \\
\hline No systemic therapy & $7(16)$ \\
\hline Information not available & $2(4)$ \\
\hline
\end{tabular}

*based on an exact Wilcoxon rank sum test to handle tied observations for comparing the distributions of c-Met expressions between characteristic groups. FNG, Fuhrman nuclear grade.

\section{Clinical outcomes by c-Met expression and treatment effect of VEGF-TT on c-Met expression}

Forty-three patients had clinical treatment information available. Twenty patients received treatment with VEGF-TT in the first-line setting, 7 received no systemic therapy and 16 were treated with vaccinebased or other therapies. In a descriptive analysis of the 20 patients treated with VEGF-TT, those with high primary c-Met expression had numerically worse timeto-treatment failure (TTF) compared to those with low c-Met expression (estimated median TTF (95\% confidence interval, CI): 6.1 (5.3-NA) vs. 9.3 (2.56-NA) months). Similarly, those with high primary c-Met expression had numerically worse overall survival (OS) compared to those with low c-Met expression (median OS $(95 \% \mathrm{CI})$ : 18.1 (12.1-NA) vs. 34.6 (11.4-NA) months).

Among eight patients who received systemic therapy in between surgical resection of their primary and metastatic sites, 6 patients were treated with VEGF-TT. Thirty-five patients had no systemic therapy in between primary and metastases resection. Patients treated with VEGF-TT in between surgical resection of primary tumor and metastases appeared to have greater c-Met expression in their metastatic sites compared to those who had no systemic treatment in between surgeries (average c-Met CS 69.2 vs. 40.0, respectively). In contrast, c-Met expression in primary tumors was similar in patients who received VEGF-TT before resection of metastases and those who received no treatment (average c-Met CS 20.0 vs. 27.5, respectively). 
Table 2: Associations of c-Met expression with FNG, T-stage, and PD-L1 status, according to tumor site

\begin{tabular}{|c|c|c|c|c|c|c|}
\hline \multirow[b]{2}{*}{ Characteristic } & \multicolumn{3}{|c|}{ c-Met expression in primary tumors } & \multicolumn{3}{|c|}{ c-Met expression in metastatic tumors } \\
\hline & $N$ & Median (IQR) & $p$-value ${ }^{*}$ & $N$ & Median (IQR) & $p$-value ${ }^{*}$ \\
\hline FNG & & & 0.04 & & & 0.42 \\
\hline III & 32 & $20(6,43)$ & & 32 & $53(14,81)$ & \\
\hline IV & 13 & $52(20,75)$ & & 13 & $60(35,130)$ & \\
\hline T-stage & & & 0.13 & & & 0.72 \\
\hline $\mathrm{Tx}-\mathrm{T} 2$ & 20 & $24(9,38)$ & & 20 & $48(26,81)$ & \\
\hline T3-T4 & 25 & $30(12,70)$ & & 25 & $55(30,83)$ & \\
\hline PD-L1 status & & & 0.34 & & & 0.45 \\
\hline$(-), \leq 0 \%$ & 32 & $24(9,46)$ & & 36 & $51(26,81)$ & \\
\hline$(+),>0 \%$ & 13 & $30(12,64)$ & & 9 & $60(35,130)$ & \\
\hline
\end{tabular}

\section{DISCUSSION}

We demonstrate that in our cohort of ccRCC samples, c-Met expression is significantly higher in corresponding metastatic sites compared to paired primary tissues. Given that the treatment landscape for mRCC has expanded to include small-molecule inhibition of VEGFR, MET, and AXL pathways [14-16], our findings are informative in that they suggest that testing for biomarkers of response to c-Met inhibitors should be
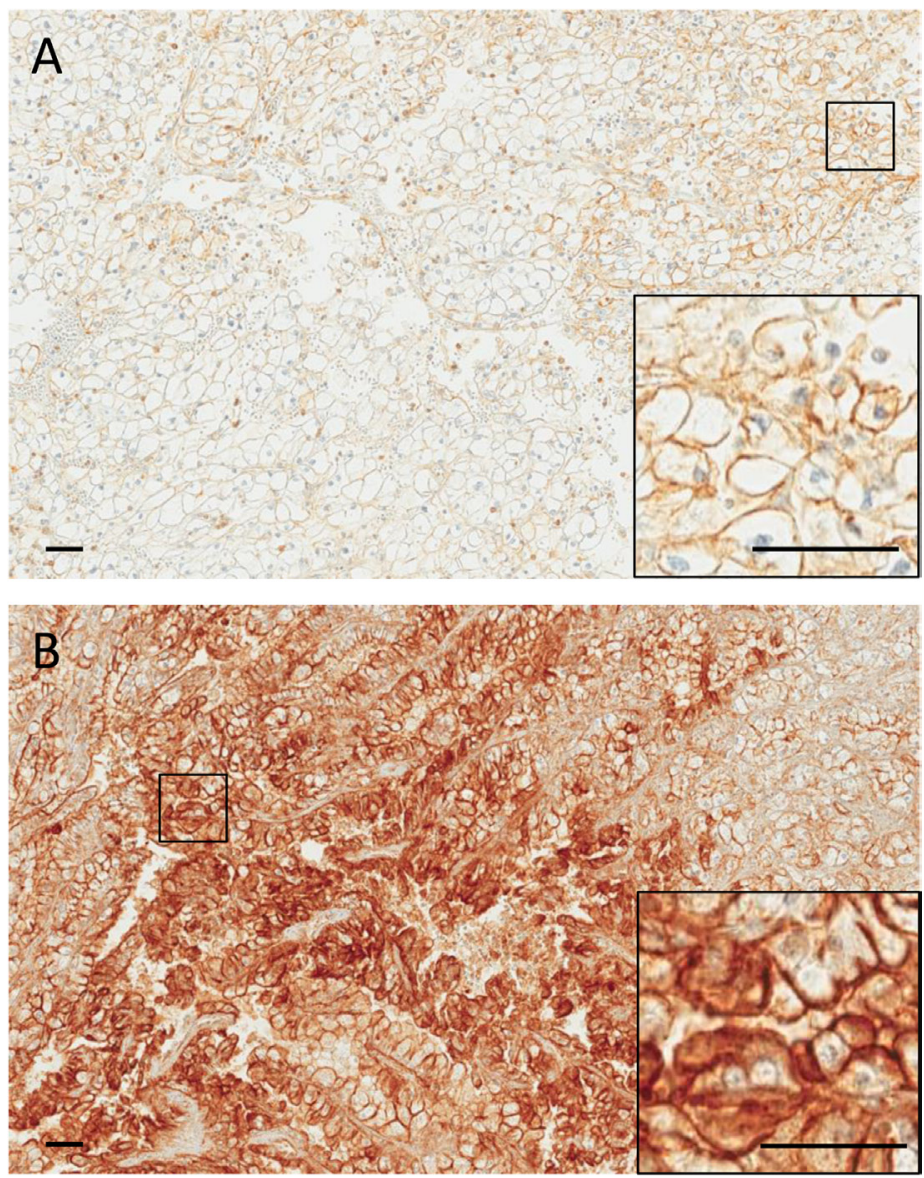

Figure 1: Representative images of a primary ccRCC (A) and its corresponding metastasis (B) immunostained for c-Met. A, weak (1+) membranous staining is observed in a subset of tumor cells. B, intense (3+) membranous staining is observed in a large fraction of tumor cells. Insets show higher magnifications of the selected areas. Scale bars: $50 \mu \mathrm{m}$. 
conducted in metastases. We further note that higher c-Met expression is seen with higher FNG and T-stage, which underscores the key role of the $c$-MET proto-oncogene in tumor development and aggressiveness [1-3].

While c-Met has been shown to be a key player in the development and progression of a variety of solid tumors, it has therapeutic, and potentially diagnostic, relevance in RCC. As a consequence of hypoxia and inactivation of the Von-Hippel-Lindau tumor suppressor gene (VHL), MET and AXL are upregulated [8,9]. These pathways are also mechanisms for resistance to antiangiogenic therapy $[10-13,23]$. This knowledge provides therapeutic rationale for inhibition of these pathways to improve outcomes in RCC, as evidenced by the development of cabozantanib [14-16]. However, identifying biomarkers of response to c-Met inhibitors, in RCC or other cancers, has been elusive. MacherGoeppinger et al. evaluated the prognostic significance of Met molecular status using tissue microarrays (TMAs) of primary tumor and corresponding normal renal tissue samples, and found higher Met expression and copy number associated with dedifferentiation and higher tumor extent. However, $84 \%$ of their samples were lowgrade (FNG 1 or 2 ) and only 2 samples overall were FNG 4. Furthermore, they did not evaluate paired metastatic samples compared to the primary RCC tissues [24]. Shuch et al. investigated Met expression in matched metastatic and primary ccRCC and found no significant difference between the two sites. Their analysis showed a low level of correlation of Met expressions between the primary and distant tissue (correlation coefficient $R=0.5$ ), and their study was limited by a smaller sample size $(n=31)$ [25]. Given that the primary tumor expression did not correlate well with that of the metastases, and knowing that systemic therapy is used to treat metastatic disease, collectively these data and our findings suggest that correlative biomarker analyses for c-Met should utilize metastatic tissue sites.

An interesting finding in our study is that PDL1 positive tumors were noted to exhibit numerically higher c-Met expression than PD-L1 negative tumors, in both primary and metastatic sites (Table 2, Figures 2, 3 A-D). This is consistent with and builds upon preclinical work by Balan et al., which identified c-Met and PDL1 to be significantly upregulated and co-localized in renal cancer tissues [19]. In a clinical study of resected primary ccRCC samples, Shin et al. show that PD-L1 positivity was significantly associated with increased c-Met expression [26]. Further, Kammerer-Jacquet et al. found that in 62 sunitnib-treated $\mathrm{mRCC}$ patients with high c-Met expression, $85.5 \%$ of these also had PDL1 overexpression (defined as 2-3 staining intensity)

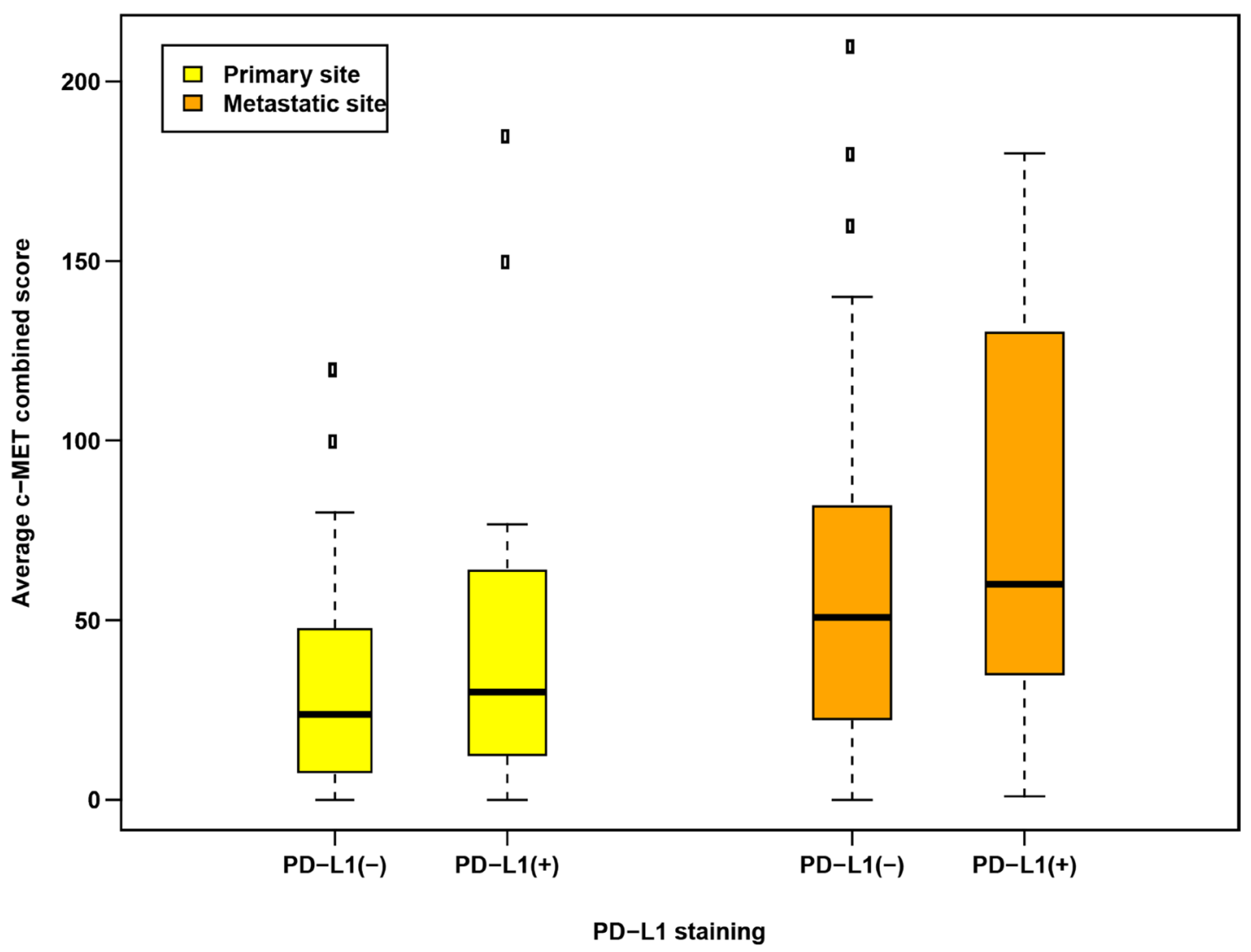

Figure 2: Distributions of c-Met expression according to PD-L1 staining positivity (PD-L1+, $>0 \%$ positive cells vs. PD-L1-, = $0 \%$ positive cells) based on tumor sample sites. 
[27]. Collectively, these data suggest a mechanism by which c-Met can promote increased survival of renal cancer cells through the regulation of PD-L1. Molnarfi et al. highlight the role of HGF/c-Met pathway as a potential regulator of inflammation and autoimmunity, particularly with immune-related systemic diseases. For example, HGF treatment can increase the levels of PDL1 expression by dendritic cells and CTLA-4 molecules expressed on $\mathrm{T}$ cells, thereby inducing immune tolerance. HGF also markedly alters the antigen-presenting function and differentiation of dendritic cells and interferes with pro-inflammatory NF- $\mathrm{KB}$ signaling, thereby inhibiting an inflammatory response [19]. In the context of this biological rationale, our results expand on the interplay between c-Met and PD-L1 as it pertains to human mRCC. While our data require larger, prospective validation, this understanding appears to support the emerging data of c-Met and PD-L1 as rational targets for combination therapeutic trials, such as the ongoing Phase I CaboNivo study (NCT02496208) [28]. With the promise of current and ongoing investigations into c-Met inhibition and PD-1/PD-L1 treatment in RCC, the need for appropriate
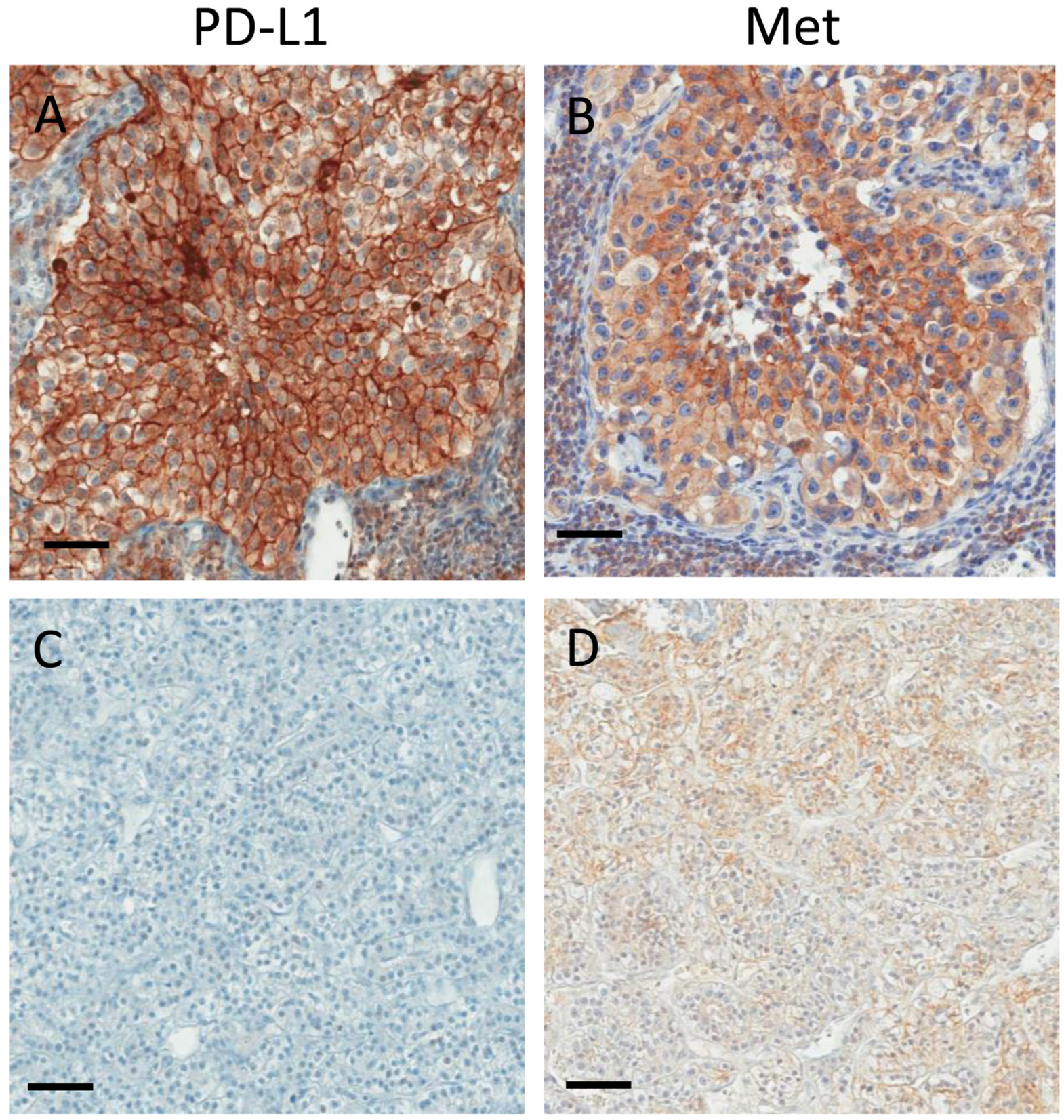

Figure 3: Representative images of two ccRCC metastases immunostained for PD-L1 (A, C) and c-Met (Met; B, D). PD-L1 positive metastasis (A) with intense (3+) membranous c-Met staining (B). PD-L1 negative metastasis (C) with weak (1+) membranous c-Met staining (D). Scale bars: $50 \mu \mathrm{m}$. 
tissue sampling to facilitate effective biomarker analysis will be important for patient selection and rational clinical trial design.

In a descriptive analysis, we observed that patients in our cohort who were treated with VEGF-TT and had high c-Met expression had numerically worse clinical outcomes, in terms of reduced TTF and OS, compared to those patients treated with VEGF-TT who had low c-Met expression. While our small sample size limited formal statistical testing, our findings are consistent with other data showing that high c-Met expression portends worse clinical prognosis $[5,7,9,14,15]$. Furthermore, we observed that patients treated with VEGF-TT in between the resection of their primary $\mathrm{RCC}$ and subsequent metastasis had numerically higher c-Met expression in metastatic sites compared to those who did not receive systemic therapy before the resection of the metastases. Plausible explanations may include the treatment effect of agents that predominantly target the VEGFR (such as sunitinib and pazopanib) and the subsequent increase in MET and AXL pathways that have been implicated in developing resistance to VEGFR inhibition [10-13]. Collectively, these findings further highlight the biological rationale for targeting VEGFR, MET, and AXL pathways in the treatment of RCC [14-16].

In this analysis of paired primary and metastatic samples, we used a validated anti-MET monoclonal antibody (MET4 antibody, GFVW, Van Andel Research Institute) and all tumor slides underwent independent pathological review and were scored by an expert genitourinary pathologist (SS). FNG was assessed using established criteria [21]. Nevertheless, our study does have some limitations. Common to most PD-L1 staining reports is the issue of variability in PD-L1 staining methodologies, given the lack of a widely-accepted, common, standard assay. We utilized a PD-L1 positivity definition as $>0 \%$ positive cells (i.e. when any tumor cell positivity was detected) given that the correlation between specific PD-L1 levels and inhibition of anti-cancer immunity is not currently well-established and that the optimal cutoff for PD-L1 expression as a biomarker for response to treatment is still unknown. This definition was also used in the context that the pathologist-based evaluation is semi-quantitative and subjective [22]. Finally, our findings would benefit from larger, prospective validation, particularly with respect to the correlation of staining with clinical outcomes and determination of an optimal cutpoint.

In conclusion, we demonstrate that c-Met expression is higher in metastatic sites compared to paired primary tissues in patients with ccRCC. Given the expanding role and ongoing clinical trials of c-Met inhibition in $\mathrm{mRCC}$, our results suggest that the accurate assessment of c-Met expression as a biomarker for these agents should be conducted in metastatic sites. Although the observation of higher c-Met expression in PD-L1+ tumors requires further investigation, it supports the growing rationale for exploring these targets in combination therapeutic trials.

\section{MATERIALS AND METHODS}

\section{Patients and samples}

A cohort of primary ccRCC tumors and the corresponding metastatic sites from 53 patients, who had undergone surgical tumor resections, were identified from two institutions: Brigham and Women's Hospital and Beth Israel Deaconess Medical Center. Formalin-fixed paraffin-embedded (FFPE) tissue blocks from primary tumor and corresponding regional lymph node or distant metastases were retrieved. For each nephrectomy or metastasectomy specimen, all hematoxylin and eosinstained slides containing tumor were reviewed by an expert genitourinary pathologist (SS). Fuhrman nuclear grade (FNG) was assessed using established criteria [21]. For each specimen, both areas of highest FNG and areas of predominant nuclear grade were selected for analysis. The study was approved by the local institutional review boards and was conducted in accordance with Good Clinical Practice Guidelines and the Declaration of Helskinki.

\section{Immunohistochemistry}

c-Met expression was evaluated by immunohistochemistry (IHC) using an anti-MET monoclonal antibody (MET4 antibody, GFVW, Van Andel Research Institute) at 1:250 dilution. Out of 53 pairs, 4 cases were excluded for insufficient tumor cells and 4 cases were excluded for failing to meet quality control (QC) for c-Met staining, resulting in 45 pairs that met the QC for IHC reporting. Therefore, the analytic cohort included 45 primary tumors and 54 metastatic sites corresponding to the 45 primary tumors. c-Met expression was measured using a combined score (CS, 0-300) and calculated by: the intensity of c-Met staining (range 0-3) multiplied by the percentage $(\%)$ of positive cells (range 0-100).

PD-L1 expression was previously evaluated by IHC and quantified using an $\mathrm{H}$-score, as reported by Callea et al [22]. Specifically, PD-L1 expression was evaluated using a mouse monoclonal anti-PD-L1 antibody (405.9A11) developed by Dr. Gordon Freeman (Boston, MA). The assay was validated using FFPE cell line controls that were known to be either positive or negative for PD-L1 expression by flow cytometry. Tumor sections were stained with the anti-PD-L1 antibody on a Benchmark XT autostainer (Ventana Medical System) with standard antigen retrieval (\#950-124, Ventana). An UltraView Universal DAB Detection kit (\#760-500, Ventana) was used per the manufacturer's instruction. Counterstaining was performed as part of the automated staining protocol 
using hematoxylin (\#760-2021, Ventana). Thereafter, slides were washed in soapy water and distilled water, dehydrated in graded alcohol and xylene, mounted and cover slipped. A case was considered positive for PD-L1 when any tumor cell membrane positivity was detected (PD-L1+ defined as PD-L1 $>0 \%$ positive cells) or else as PD-L1- (=0\% positive cells $)$.

\section{Statistical analysis}

Patient and tumor characteristics at the time of primary surgery were summarized descriptively. When several samples were available within one primary or multiple metastatic sites, an average of c-Met combined score (average c-Met CS) were calculated. Similarly, the PD-L1 expressions according to tumor sites were dichotomized as PD-L1+ ( $>0 \%$ positive cells $)$ and PDL1- ( $=0 \%$ positive cells) in the analysis. The comparisons between paired primary and metastatic samples used Wilcoxon signed-rank test for c-Met expression status (average c-Met CS). The associations of the average c-Met CS with PD-L1 expression $(+/-)$, as well as clinicopathological features of $\mathrm{FNG}$ and tumor stage (T-stage) according to the primary and metastatic sites were assessed using the Wilcoxon rank-sum test. In an exploratory analysis of patients treated with first-line VEGF-TT, time to treatment failure (TTF) and overall survival (OS) were estimated using the Kaplan Meier method, according to high c-Met expression levels (defined as c-Met $\mathrm{CS} \geq$ median) versus low (c-Met $\mathrm{CS}<$ median). Descriptive statistics were also used to summarize c-Met expression by disease sites (primary vs. metastasis) in patients who had VEGF-TT in between sampling time points compared to those without treatment prior to sampling. All statistical computations were performed using R 13.3.1 (www.r-project.org), and a $p$-value (two-sided) of $<0.05$ was considered statistically significant when appropriate.

\section{Author contributions}

AAL, LA, MC, TKC, SS were involved in conceptualization of the study; AAL, LA, MC, JCP, TKC, SS were involved in study investigation; AAL, KPG were involved in data generation and analysis; AAL, KPG, $\mathrm{TKC}$, SS were involved in original manuscript drafting; all authors were involved in manuscript review and editing.

\section{CONFLICTS OF INTEREST}

AAL: educational travel support from Pfizer. KPG: stock and other ownership interests in MDGN. LA: research funding from Novartis and Pfizer; advisory role at Novartis, Pfizer, Amgen and Sanofi. DFM: consulting/advisory role at Alexion Pharmaceuticals, Array BioPharma, Bristol-Myers Squibb, Eisai, Exelixis,
Genentech/Roche, Merck, Novartis, Pfizer, X4 Pharma; institutional research funding from Prometheus Labs. MBA: honoraria from Bristol-Myers Squibb; consulting/ advisory role at Alkermes, Amgen, Bristol-Myers Squibb, C-Cam, Genentech, Genoptix, GlaxoSmithKline, Infinity Pharmaceuticals, Lilly, Merck, Nektar, Novartis, Pfizer, X4 Pharma. LCH: consulting/advisory role at Dendreon, Genentech, KEW Group, Medivation/Astellas, NCCN, Pfizer, PlatformQ Health, Theragene; institutional research funding from Bayer, Dendreon, Genentech/ Roche, Medivation/Astellas, Sotio, Takeda, BristolMyers Squibb; Travel, Accommodations, and Expenses from Sanofi. TKC: honoraria from NCCN, UpToDate; consulting/advisory role at Bayer, Bristol-Myers Squibb, GlaxoSmithKline, Merck, Novartis, Pfizer; institutional research funding from AstraZeneca, Bristol-Myers Squibb, Exelixis, GlaxoSmithKline, Merck, Novartis, Peloton Therapeutics, Pfizer, Roche/Genentech, TRACON Pharma. SS: consulting/advisory role at AstraZeneca, Merck, Verastem; institutional research funding from AstraZeneca and Exelixis; patents or other intellectual property at Biogenex. The remaining authors declare no conflicts of interest.

\section{FUNDING}

This research was supported in part by the DanaFarber/Harvard Cancer Center Kidney SPORE (DFM, TKC, SS) and the Trust Family, Michael Brigham, and Loker Pinard Funds for Kidney Cancer Research at DanaFarber Cancer Institute (TKC).

\section{REFERENCES}

1. Bottaro DP, Rubin JS, Faletto DL, Chan AM, Kmiecik TE, Vande Woude GF, Aaronson SA. Identification of the hepatocyte growth factor receptor as the c-met protooncogene product. Science. 1991; 251:802-804.

2. Peruzzi B, Bottaro DP. Targeting the c-Met signaling pathway in cancer. Clin Cancer Res. 2006; 12:3657-3660.

3. Harshman LC, Choueiri TK. Targeting the Hepatocyte Growth Factor/c-Met Signaling Pathway in Renal Cell Carcinoma. Cancer J. 2013; 19:316-323.

4. Guo B, Cen H, Tan X, Liu W, Ke Q. Prognostic value of MET gene copy number and protein expression in patients with surgically resected non-small cell lung cancer: a meta-analysis of published literatures. PLoS One. 2014; 9:e99399.

5. Gao H, Guan M, Sun Z, Bai C. High c-Met expression is a negative prognostic marker for colorectal cancer: a metaanalysis. Tumour Biol. 2015; 36:515-520.

6. Gibney GT, Aziz SA, Camp RL, Conrad P, Schwartz BE, Chen CR, Kelly WK, Kluger HM. c-Met is a prognostic marker and potential therapeutic target in clear cell renal cell carcinoma. Ann Oncol. 2013; 24:343-349. 
7. Peltola KJ, Penttila P, Rautiola J, Joensuu H, Hänninen E, Ristimäki A, Bono P. Correlation of c-Met expression and outcome in patients with renal cell carcinoma treated with sunitinib. Clin Genitourin Cancer. 2017; 15:487-494.

8. Rankin EB, Fuh KC, Castellini L, Viswanathan K, Finger EC, Diep AN, LaGory EL, Kariolis MS, Chan A, Lindgren D, Axelson H, Miao YR, Krieg AJ, et al. Direct regulation of GAS6/AXL signaling by HIF promotes renal metastasis through SRC and MET. Proc Natl Acad Sci USA. 2014; 111:13373-8.

9. Gibney GT, Aziz SA, Camp RL, Conrad P, Schwartz BE, Chen CR, Kelly WK, Kluger HM. c-Met is a prognostic marker and potential therapeutic target in clear cell renal cell carcinoma. Ann Oncol. 2013; 24:343-349.

10. Shojaei F, Lee JH, Simmons BH, Wong A, Esparza CO, Plumlee PA, Feng J, Stewart AE, Hu-Lowe DD, Christensen JG. HGF/c-Met acts as an alternative angiogenic pathway in sunitinib-resistant tumors. Cancer Res. 2010; 70:10090-100.

11. Zhou L, Liu XD, Sun M, Zhang X, German P, Bai S, Ding Z, Tannir N, Wood CG, Matin SF, Karam JA, Tamboli $\mathrm{P}$, Sircar K, et al. Targeting MET and AXL overcomes resistance to sunitinib therapy in renal cell carcinoma. Oncogene. 2016; 35:2687-97.

12. Sennino B, Ishiguro-Oonuma $\mathrm{T}$, Wei $\mathrm{Y}$, Naylor RM, Williamson CW, Bhagwandin V, Tabruyn SP, You WK, Chapman HA, Christensen JG, Aftab DT, McDonald DM. Suppression of tumor invasion and metastasis by concurrent inhibition of c-Met and VEGF signaling in pancreatic neuroendocrine tumors. Cancer Discov. 2012; 2:270-87.

13. Ciamporcero E, Miles KM, Adelaiye R, Ramakrishnan S, Shen L, Ku S, Pizzimenti S, Sennino B, Barrera G, Pili R. Combination strategy targeting VEGF and HGF/c-met in human renal cell carcinoma models. Mol Cancer Ther. 2015; 14:101-10.

14. Choueiri TK, Escudier B, Powles T, Tannir NM, Mainwaring PN, Rini BI, Hammers HJ, Donskov F, Roth BJ, Peltola K, Lee JL, Heng DY, Schmidinger M, et al. Cabozantinib versus everolimus in advanced renal cell carcinoma (METEOR): final results from a randomised, open-label, phase 3 trial. Lancet Oncol. 2016; 17:917-927

15. Choueiri TK, Escudier B, Powles T, Mainwaring PN, Rini BI, Donskov F, Hammers H, Hutson TE, Lee JL, Peltola K, Roth BJ, Bjarnason GA, Géczi L, et al. Cabozantinib versus everolimus in advanced renal cell carcinoma. N Engl J Med. 2015; 373:1814-1823.

16. Choueiri TK, Halabi S, Sanford BL, Hahn O, Michaelson MD, Walsh MK, Feldman DR, Olencki T, Picus J, Small EJ, Dakhil S, George DJ, Morris MJ. Cabozantinib versus sunitinib as initial targeted therapy for patients with metastatic renal cell carcinoma of poor or intermediate risk: The Alliance A031203 CABOSUN trial. J Clin Oncol. 2017; 35:591-597.

17. Molnarfi N, Benkhoucha M, Funakoshi H, Nakamura T, Lalive PH. Hepatocyte growth factor: A regulator of inflammation and autoimmunity. Autoimmun Rev. 2015; 14:293-303.
18. Apolo AB, Tomita Y, Lee MJ, Lee S, Frosch A, Steinberg SM, Gulley JL, Schlom J, Bottaro DP, Trepel JB. Effect of cabozantinib on immunosuppressive subsets in metastatic urothelial carcinoma. J Clin Oncol. 2014; 32:5s(suppl; abstr 4501).

19. Balan M, Mier y Teran E, Waaga-Gasser AM, Gasser M, Choueiri TK, Freeman G, Pal S. Novel roles of c-Met in the survival of renal cancer cells through the regulation of HO-1 and PD-L1 Expression. J Biol Chem. 2015; 290:8110-8120.

20. Gerlinger M, Rowan AJ, Horswell S, Math M, Larkin J, Endesfelder D, Gronroos E, Martinez P, Matthews N, Stewart A, Tarpey P, Varela I, Phillimore B, et al. Intratumor heterogeneity and branched evolution revealed by multiregion sequencing. N Engl J Med. 2012; 366:883-892.

21. Fuhrman SA, Lasky LC, Limas C. Prognostic significance of morphologic parameters in renal cell carcinoma. Am J Surg Pathol. 1982; 6:655-63.

22. Callea M, Albiges L, Gupta M, Cheng SC, Genega EM, Fay AP, Song J, Carvo I, Bhatt RS, Atkins MB, Hodi FS, Choueiri TK, McDermott DF, et al. Differential Expression of PD-L1 between primary and metastatic sites in clear-cell renal cell carcinoma. Cancer Immunol Res. 2015; 3:1158-64.

23. Ruiz-Morales JM, Heng DY. Cabozantinib in the treatment of advanced renal cell carcinoma: clinical trial evidence and experience. Ther Adv Urol. 2016; 8:338-347.

24. Macher-Goeppinger S, Keith M, Endris V, Penzel R, Tagscherer KE, Pahernik S, Hohenfellner M, Gardner H, Grüllich C, Schirmacher P, Roth W. MET expression and copy number status in clear-cell renal cell carcinoma: prognostic value and potential predictive marker. Oncotarget. 2017; 8:1046-1057. https://doi.org/10.18632/ oncotarget. 13540 .

25. Shuch B, Falbo R, Parisi F, Adeniran A, Kluger Y, Kluger HM, Jilaveanu LB. MET expression in primary and metastatic clear cell renal cell carcinoma: implications of correlative biomarker assessment to MET pathway inhibitors. Biomed Res Int. 2015; 2015:192406.

26. Shin SJ, Jeon YK, Kim PJ, Cho YM, Koh J, Chung DH, Go H. Clinicopathologic analysis of PD-L1 and PD-L2 expression in renal cell carcinoma: association with oncogenic proteins status. Ann Surg Oncol. 2016; 23:694-702.

27. Kammerer-Jacquet SF, Medane S, Bensalah K, Bernhard JC, Yacoub M, Dupuis F, Ravaud A, Verhoest G, Mathieu R, Peyronnet B, Brunot A, Laguerre B, Lespagnol A, et al. Correlation of c-MET expression with PD-L1 expression in metastatic clear cell renal cell carcinoma treated by sunitinib first-line therapy. Targ Oncol. 2017; 12:487-494.

28. Apolo AB, Mortazavi A, Stein M, Pal SK, Davarpanah N, Parnes HL, Ning YM, Francis DC, Cordes LM, Berniger M, Steinberg SM, Monk P, Lancaster T, et al. A phase I study of cabozantinib plus nivolumab (CaboNivo) in patients (pts) with refractory metastatic urothelial carcinoma (mUC) and other genitourinary (GU) tumors. Presented at: 2016 ESMO Congress; October 7-11, 2016; Copenhagen, Denmark. Abstract 774PD. 